\title{
On the Nature of Martensitic Transformation in the Ternary $\mathrm{Ni}-\mathrm{Zn}-\mathrm{Cu}$ Alloys
}

\author{
By Norihiko Nakanishi*, Masato Hayashi** and Yuichiro Murakami***
}

\begin{abstract}
The martensitic transformation from the $\mathrm{B} 2$ to $\mathrm{L} 1_{\mathrm{o}}$ structure, and the composition and tem perature dependence of the lattice parameters in the ternary $\mathrm{Ni}-\mathrm{Zn}-\mathrm{Cu}$ alloys were investigated. The axial ratio $(c / a)$ of the $\mathrm{L} 1_{\mathrm{o}}$ lattice decreased slightly with increase in temperature and showed a discontinuous drop at the $L_{1}$ to $\mathbf{B} 2$ transformation temperature. The nature of this transformation was considered to be slightly of the 2 nd order transformation, although it was almost of the 1 st order. The habit plane of this martensite was also studied. The phase stability and the characteristics of martensitic transformation in the nickel base alloys were discussed briefly as a function of the electron atom ratio $(e / a)$.
\end{abstract}

(Received July 25, 1983)

Keyzuords: martensite, nickel-zinc-copper alloy, lattice parameter, phase transformation, habit plane

\section{Introduction}

The martensitic transformation in the nickel base alloys has been investigated by many metallurgists in alloys such as $\mathrm{Ni}-\mathrm{Al}, \mathrm{Ni}-\mathrm{Zn}$, $\mathrm{Ni}-\mathrm{Zn}-\mathrm{Cu}, \mathrm{Ni}_{3} \mathrm{Sn}$ and $\mathrm{Ni}-\mathrm{Cu}-\mathrm{Sn}$. The Ni$\mathrm{Al}^{(1)-(4)}, \mathrm{Ni}-\mathrm{Zn}^{(5)-(8)}$ and $\mathrm{Ni}-\mathrm{Zn}-\mathrm{Cu}^{(9)-(13)}$ alloys undergo a martensitic transformation from the $\mathrm{CsCl}(\mathrm{B} 2)$-type ordered cubic phase $\left(\beta_{2}\right)$ to the $\mathrm{AuCuI}\left(\mathrm{L} 1_{\mathrm{o}}\right)$-type ordered tetragonal structure $\left(\alpha_{2}^{\prime}\right)$, and the $\mathrm{Ni}_{3} \mathrm{Sn}^{(14)}$ and $\mathrm{Ni}-\mathrm{Cu}-$ $\mathrm{Sn}^{(15)(16)}$ alloys from the $\mathrm{DO}_{3}$-type ordered cubic phase $\left(\beta_{1}\right)$ to the $2 \mathrm{H}$-type orthorhombic structure $\left(\gamma_{1}^{\prime}\right)$. In the $\mathrm{Ni}-\mathrm{Al}$ and $\mathrm{Ni}-\mathrm{Zn}-\mathrm{Cu}$ alloys, the martensitic transformation has been reported to be thermoelastic ${ }^{(3)(13)}$, and the shape memory effect has been observed ${ }^{(2)(12)}$. Considering the increasing interest on the shape memory effect in Ti-Ni and noble metal base $\beta$ phase alloys ${ }^{(17)}$, it is important to study the martensitic transformation also in the nickel base alloys.

In the binary $\mathrm{Ni}-\mathrm{Zn}$ alloy, the starting temperature of the $\mathrm{B} 2$ to $\mathrm{L}_{\mathrm{o}}$ transformation upon

* Department of Chemistry, Faculty of Science, Konan University, Kobe 658, Japan.

** Graduate Student, Konan University, Kobe. Present address: New Nippon Electric Co., Ltd., Ohtsu 550, Japan.

*** Department of Chemistry, Faculty of Science, Kyoto University, Kyoto 606, Japan. cooling is very high (950-1080 $\mathrm{K}$ depending on composition $)^{(5)(18)}$. This transformation temperature has been found to be depressed by the substitution of $\mathrm{Cu}$ for $\mathrm{Ni}$ atoms in $\mathrm{Ni}_{100-x-y}$ $\mathrm{Zn}_{y} \mathrm{Cu}_{x}\left(y=48\right.$ and 50) alloys ${ }^{(10)(11)}$; the starting temperature of the martensitic transformation upon cooling, $M_{s}$, is about $290 \mathrm{~K}$, when $x$ equals about 20.5 and 18 in alloys with $y=48$ and 50 , respectively. In the ternary $\mathrm{Ni}-\mathrm{Zn}-\mathrm{Cu}$ alloys having $\mathrm{Zn}$ concentration more than 50 at $\%$, the martensitic transformation and the composition dependence of lattice parameters have not been studied until now. Moreover, in the binary $\mathrm{Ni}-\mathrm{Zn}$ alloy, the axial ratio $(c / a)$ of the $\mathrm{L} 1_{\mathrm{o}}$ lattice has been shown to decrease slightly, when the temperature has increased up to the transformation temperature ${ }^{(8)}$, suggesting that the $\mathrm{L}_{\mathrm{o}}$ to $\mathrm{B} 2$ transformation in the $\mathrm{Ni}-\mathrm{Zn}$ alloy has slightly the nature of the 2 nd order transformation. Then in the present work, the composition and temperature dependence of the lattice parameters and phase relation in the $\mathrm{Ni}_{100-x-y} \mathrm{Zn}_{y} \mathrm{Cu}_{x}(y=52,54$ and 56) alloys were investigated by $\mathrm{X}$-ray diffraction and optical microscopy. The habit plane of the Ni$\mathrm{Zn}-\mathrm{Cu}$ martensite was also analyzed by electron microscopy.

\section{Experimental}

The $\mathrm{Ni}-\mathrm{Zn}-\mathrm{Cu}$ alloys were prepared by powder metallurgy techniques. The metal powders 
with $99.99 \%$ purity were compressed at room temperature and then sintered at $1123 \mathrm{~K}$ for $360 \mathrm{ks}$. Specimen for X-ray analysis was quenched into water at $273 \mathrm{~K}$ after annealing at $1123 \mathrm{~K}$ for $300 \mathrm{~s}$. Specimens for optical and electron microscopy were prepared by melting of sintered specimens in an evacuated quartz tube at a high temperature near $1300 \mathrm{~K}$ and then quenched into water at $273 \mathrm{~K}$ after annealing at $1123 \mathrm{~K}$ for $72 \mathrm{ks}$. This specimen was cut and polished into a disc $3 \mathrm{~mm}$ in diameter and about $0.2 \mathrm{~mm}$ in thickness and quenched from $1023 \mathrm{~K}$ to $273 \mathrm{~K}$. This disc specimen was polished by the jet polishing method using a $20 \% \mathrm{H}_{2} \mathrm{SO}_{4}$ solution in methanol. The habit plane was studied by the trace analysis using an electron microscope. This microscope and an X-ray diffractometer used were JEM-100CX and Rigaku RU-3L, respectively.

\section{Results}

An optical micrograph of a $\mathrm{Ni}_{40} \mathrm{Zn}_{50} \mathrm{Cu}_{10}$ alloy cooled in a furnace is shown in Fig. 1, where the surface relief is observed: the cooling rate is about $0.21 \mathrm{~K} / \mathrm{s}$, and the $M_{s}$ temperature of this alloy is about $883 \mathrm{~K}$. The surface relief in the quenched specimen of $\mathrm{Ni}-\mathrm{Zn}-\mathrm{Cu}$ alloy has been already reported in the previous papers ${ }^{(12)(13)}$. In the case of the $\mathrm{Ni}_{40} \mathrm{Zn}_{50} \mathrm{Cu}_{10}$ alloy, the surface relief is observed even in a furnace cooled specimen. Then, even during slow cooling, the $\mathrm{B} 2$ to $\mathrm{L}_{\mathrm{o}}$ transformation in the $\mathrm{Ni}-\mathrm{Zn}-\mathrm{Cu}$ alloys is considered to be martensitic in a range of composition where the

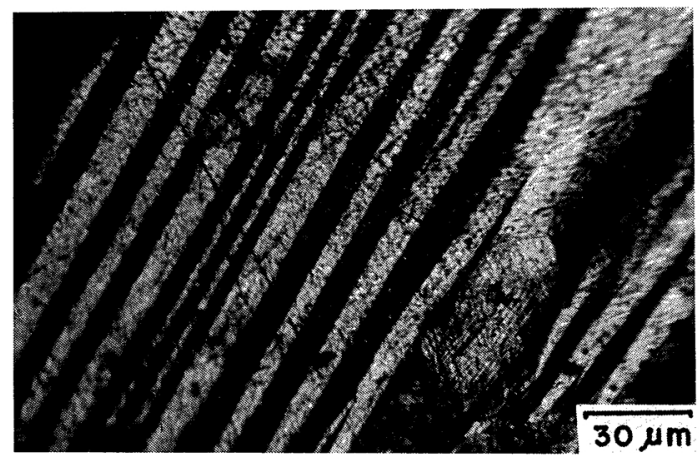

Fig. 1 Surface relief of a $\mathrm{Ni}_{40} \mathrm{Zn}_{50} \mathrm{Cu}_{10}$ martensite cooled in a furnace from $1123 \mathrm{~K}$ to room temperature.

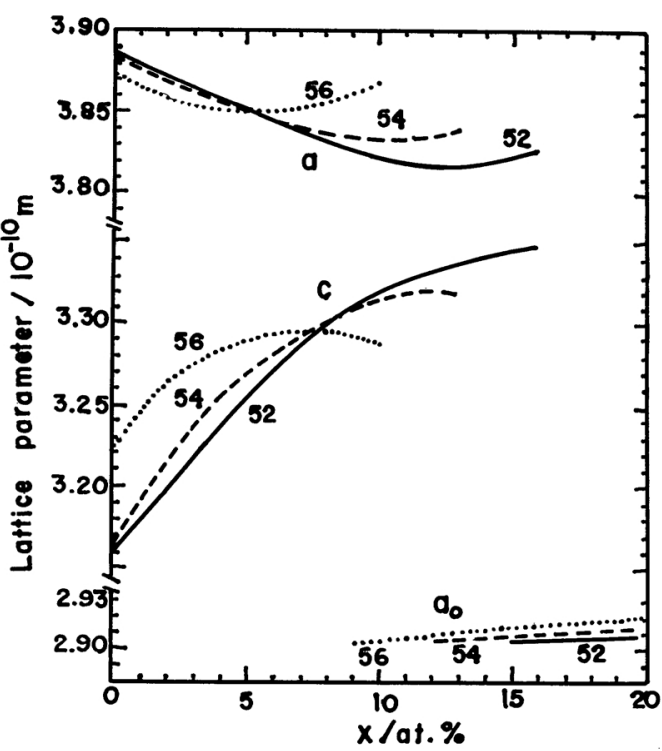

Fig. 2 Lattice parameters of $\mathrm{Ni}_{100-x-y} \mathrm{Zn}_{y} \mathrm{Cu}_{x}(y=$ 52,54 and 56) alloys as a function of $\mathrm{Cu}$ content $(x)$ at room temperature. $a$ and $c$ show the lattice parameters of the $\mathrm{L} 1_{0}$ lattice, and $a_{0}$ that of the $\mathrm{B} 2$ lattice. The numbers in the figure represent the concentration of $\mathrm{Zn}(y)$. The axial ratio $(c / a)$ in these alloys is shown in Fig. 3.

$M_{s}$ temperature is below about $880 \mathrm{~K}^{\dagger}$.

The composition dependence of lattice parameters in the $\mathrm{Ni}_{100-x-y} \mathrm{Zn}_{y} \mathrm{Cu}_{x}$ alloys $(y=52$, 54 and 56) observed at room temperature is shown in Fig. 2. The $a$ axis of the $\mathrm{L} 1_{0}$ lattice decreases with increase in $x$ (composition of $\mathrm{Cu}$ ) in a range of small $x$ and then increases with increase in $x$ after a minimum. The $c$ axis, on the contrary, increases with increase in $x$ in a range of small $x$. The slope of the $c$-vs- $x$ curve decreases, as the composition, $x$, approaches the phase boundary between $\mathrm{L} 1_{\mathrm{o}}$ and $\mathrm{B} 2$ structures. By the phase change from $\mathrm{L1}_{0}$ to $\mathrm{B} 2$, the $a$ axis is expanded to the value of $\sqrt{2} a_{\mathrm{o}}$ and the $c$ axis shrinks to $a_{\mathrm{o}}$, where $a_{\mathrm{o}}$ is the lattice parameter of the $B 2$ lattice. The change in the

$\dagger$ In the binary $\mathrm{Ni}_{50} \mathrm{Zn}_{50}$ alloy ${ }^{(7)}$, the $\mathrm{B} 2$ to $\mathbf{L 1}_{0}$ transformation has been shown to be martensitic in the case of quenching and massive in the case of furnace cooling (the starting temperature of this transformation upon cooling is $1033 \mathrm{~K}$ ). The B2 to $\mathrm{L}_{\mathrm{o}}$ transformation is considered to be martensitic in a temperature range where the migration of interface occurs very slowly. 
slope of the $a$ (or $c$ )-vs- $x$ curve in a range of $x$ near the phase boundary is suggested to be due to the fact that the $\mathrm{L} 1_{\mathrm{o}}$ to $\mathrm{B} 2$ transformation has slightly the nature of the 2 nd order transformation, which will be discussed later.

The axial ratio $(c / a)$ of the $L 1_{o}$ lattice in the $\mathrm{Ni}_{100-x-y} \mathrm{Zn}_{y} \mathrm{Cu}_{x}(y=52,54$ and 56) alloys observed at room temperature is shown as a function of the electron atom ratio $(e / a)$ in Fig. 3, together with the results in the alloys

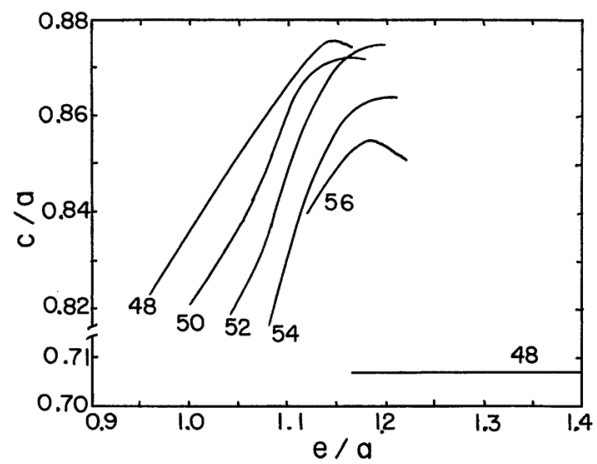

Fig. 3 The axial ratio (c/a) of the $\mathrm{L} 1$ o lattice in $\mathrm{Ni}_{100-x-y} \mathrm{Zn}_{y} \mathrm{Cu}_{x}(y=48,50,52,54$ and 56) alloys as a function of electron atom ratio $(e / a)$ at room temperature. The line with $c / a=0.707$ shows the existence of the B2 lattice in alloy with $y=48$. For the range of the existence of $\mathbf{B} 2$ structure in other compositions, see Fig. 2 and refs. (10) and (11). The numbers in the figure represent the concentration of $\mathrm{Zn}(y) . e / a$ of these alloys is given by $(x+2 y) / 100$. with $y=48$ and $50^{(10)(11)}$. In the calculation of $e / a$, only the number of $\mathrm{s}+\mathrm{p}$ electrons is taken into account, and $e / a$ of $\mathrm{Ni}, \mathrm{Cu}$ and $\mathrm{Zn}$ atoms is assumed to be 0,1 and 2 , respectively. The axial ratio of the $\mathrm{B} 2$ lattice is shown to be 0.707 in this figure, because the B2 lattice is equal to the $\mathrm{L1}_{\mathrm{o}}$ lattice with $c / a=1 / \sqrt{2}$. The axial ratio increases with increasing $e / a$ in the $\mathrm{L}_{\mathrm{o}}$ phase, and when the $e / a$ of an alloy approaches that of the phase boundary, the slope of the $c / a$-vs-e/a curve decreases gradually in the $\mathrm{L} 1_{\mathrm{o}}$ phase. The axial ratio of the $\mathrm{L}_{\mathrm{o}}$ phase drops discontinuously down to 0.707 by the phase change from $\mathrm{L} 1_{\mathrm{o}}$ to $\mathrm{B} 2$. The $e / a$ at the phase boundary is not constant but increases very slightly with increase in $\mathrm{Zn}$ content, as shown in Fig. 3.

The temperature dependence of the lattice parameters in the $\mathrm{Ni}_{34} \mathrm{Zn}_{52} \mathrm{Cu}_{14}, \mathrm{Ni}_{36} \mathrm{Zn}_{54}$ $\mathrm{Cu}_{10}$ and $\mathrm{Ni}_{36} \mathrm{Zn}_{56} \mathrm{Cu}_{8}$ alloys are shown in Fig. 4 . In the $\mathrm{L} 1_{\mathrm{o}}$ phase, the $a$ axis increases and $c$ axis decreases gradually with increase in temperature. By the $\mathrm{L}_{0}$ to $\mathrm{B} 2$ transformation, the $a$ axis jumps discontinuously up to the value of $\sqrt{2} a_{\mathrm{o}}$ and the $c$ axis drops down to $a_{\mathrm{o}}$. The temperature dependence of the axial ratio $(c / a)$ of the $\mathrm{L} 1_{\mathrm{o}}$ lattice in these alloys is also shown in Fig. 5. The axial ratio decreases with increase in temperature and drops discontinuously down to 0.707 by the $\mathrm{L} 1_{\mathrm{o}}$ to $\mathrm{B} 2$ transformation. This tendency of the axial ratio depending on

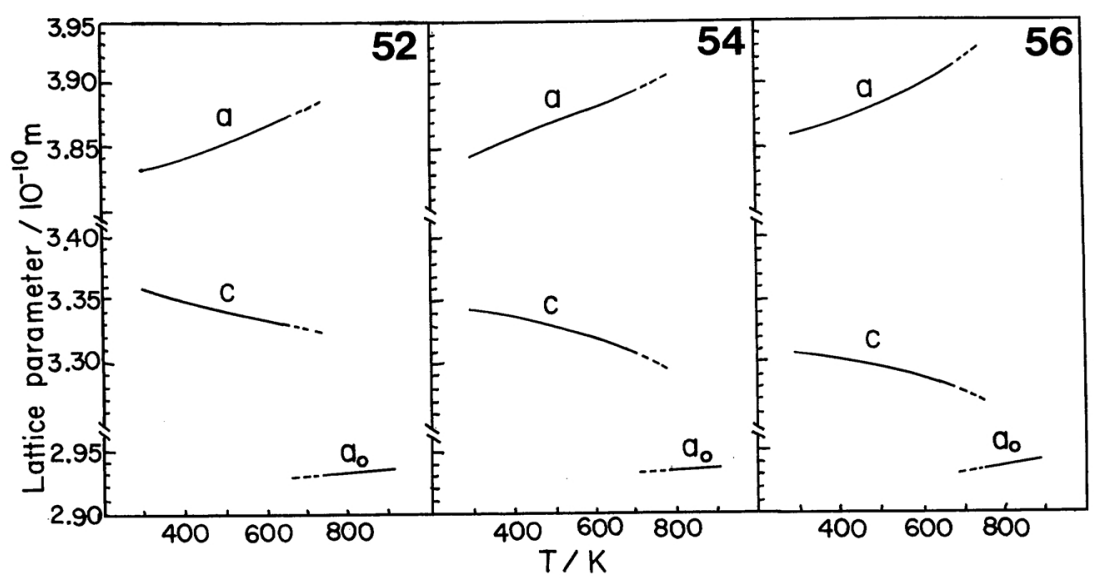

Fig. 4 Temperature dependence of the lattice parameters in $\mathrm{Ni}_{34} \mathrm{Zn}_{52} \mathrm{Cu}_{14}, \mathrm{Ni}_{36} \mathrm{Zn}_{54} \mathrm{Cu}_{10}$ and $\mathrm{Ni}_{36} \mathrm{Zn}_{56} \mathrm{Cu}_{8}$ alloys. $a, c$ and $c_{\mathrm{o}}$ means the same parameters as those in Fig. 2. Numbers in the figure represent the concentration of $\mathrm{Zn}$ in these specimens. The dotted lines show the region where the coexistence of the $\mathrm{L1}_{\mathrm{o}}$ and $\mathrm{B} 2$ structures was observed. The axial ratio $(c / a)$ in these alloys is shown in Fig. 5. 
temperature is similar to that depending on $e / a$ shown in Fig. 3 and suggests that the $\mathrm{L} 1_{\mathrm{o}}$ to $\mathrm{B} 2$ transformation has slightly the 2 nd order nature although it is almost of the 1st order transformation.

The change in atomic volume $(\Delta V)$ accompanying the $\mathbf{L} 1_{0}$ to $\mathbf{B} 2$ transformation upon heating, which was measured by X-ray diffraction in several $\mathrm{Ni}-\mathrm{Zn}-\mathrm{Cu}$ alloys, is listed in Table 1: $\Delta V$ is in a range from 0.16 to $0.48 \%$ in these alloys. The change in atomic volume $(\Delta V)$ accompanying with the martensitic transformation has been reported to be about 2.2$2.7 \%$ in the $\mathrm{Fe}-\mathrm{Ni}$ alloy ${ }^{(19)}$ and in the order of $0.3 \%$ in the $\beta$ phase alloy ${ }^{(20)}$. The value of $\Delta V$

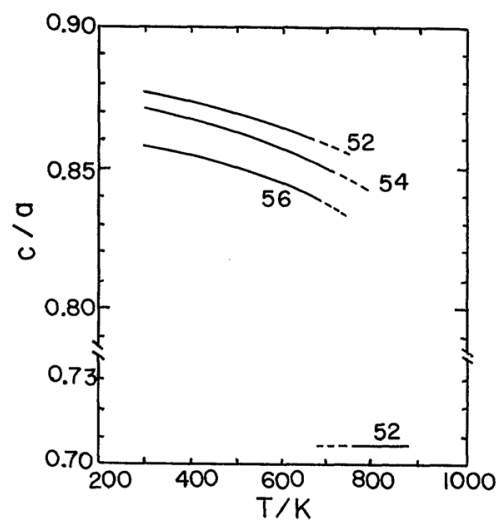

Fig. 5 Temperature dependence of the axial ratio (c/a) of the $\mathrm{L} 1_{0}$ lattice in $\mathrm{Ni}_{34} \mathrm{Zn}_{52} \mathrm{Cu}_{14}, \mathrm{Ni}_{36} \mathrm{Zn}_{54}$ $\mathrm{Cu}_{10}$ and $\mathrm{Ni}_{36} \mathrm{Zn}_{56} \mathrm{Cu}_{8}$ alloys. The line with $c / a=$ 0.707 shows the existence of the $\mathrm{B} 2$ structure in $\mathrm{Ni}_{34} \mathrm{Zn}_{52} \mathrm{Cu}_{14}$ alloy. The dotted line shows the region where the coexistence of the $\mathrm{L1}_{0}$ and $\mathrm{B} 2$ structures was observed. For the range of the existence of B2 structure in other compositions, see Fig. 4. The numbers in the figure show the concentration of $\mathrm{Zn}$ in these specimens.

Table 1 The increase of atomic volume $(\Delta V)$ associated with the $\mathrm{L} 1_{0}$ to $\mathrm{B} 2$ transformation upon heating in $\mathrm{Ni}-\mathrm{Zn}-\mathrm{Cu}$ alloys. The starting temperature of $\mathrm{L} 1_{\mathrm{o}}$ to B2 transformation upon heating, $\boldsymbol{A}_{s}$, of these alloys is also shown in this table.

\begin{tabular}{lll}
\hline \hline $\mathrm{Ni}-\mathrm{Zn}-\mathrm{Cu}$ alloy & $\Delta V / \%$ & $A_{s} / \mathrm{K}$ \\
\hline $\mathrm{Ni}-52 \mathrm{Zn}-14 \mathrm{Cu}$ & 0.16 & 670 \\
$\mathrm{Ni}-54 \mathrm{Zn}-10 \mathrm{Cu}$ & 0.475 & 710 \\
$\mathrm{Ni}-54 \mathrm{Zn}-14 \mathrm{Cu}$ & 0.32 & 230 \\
$\mathrm{Ni}-56 \mathrm{Zn}-8 \mathrm{Cu}$ & 0.48 & 675 \\
$\mathrm{Ni}-56 \mathrm{Zn}-10 \mathrm{Cu}$ & 0.24 & 250 \\
\hline \hline
\end{tabular}

in the $\mathrm{Ni}-\mathrm{Zn}-\mathrm{Cu}$ alloy is in the same order as that in the $\beta$ phase alloy which undergoes a thermoelastic martensitic transformation.

The contour line where the $M_{s}$ temperature of the ternary $\mathrm{Ni}-\mathrm{Zn}-\mathrm{Cu}$ alloy is $293 \mathrm{~K}$ is shown in Fig. 6. The composition of $\mathrm{Cu}$ on this line decreases with increase in $\mathrm{Zn}$ content. The $e / a$ on this line is not constant, but increases very slightly with increase in $\mathrm{Zn}$ content, which was also represented in Fig. 3. The composition dependence of the $M_{s}$ temperature in the ternary $\mathrm{Ni}-\mathrm{Zn}-\mathrm{Cu}$ alloys has been reported in the previous papers $^{(10)(11)}$.

The habit plane of the $\mathrm{Ni}_{31.5} \mathrm{Zn}_{48} \mathrm{Cu}_{20.5}$ martensite was investigated by the trace analysis in several specimens with different orientations by electron microscopy. The traces of the habit

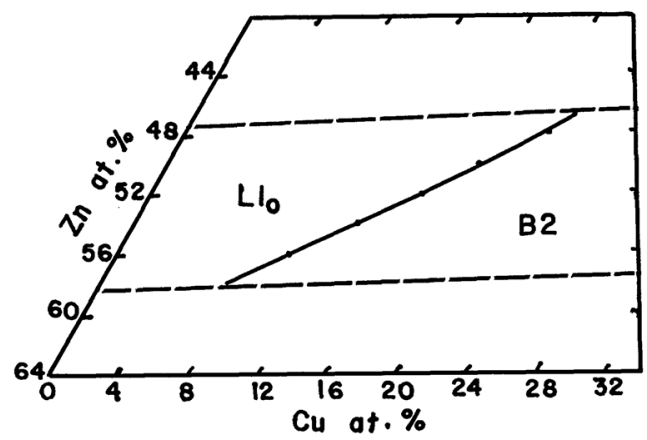

Fig. 6 Phase relation in the ternary $\mathrm{Ni}-\mathrm{Zn}-\mathrm{Cu}$ alloys. The full line shows the contour line where the $M_{s}$ temperature is $293 \mathrm{~K}$. The dashed line represents the phase boundary of the B2 phase at a temperature $123 \mathrm{~K}$.

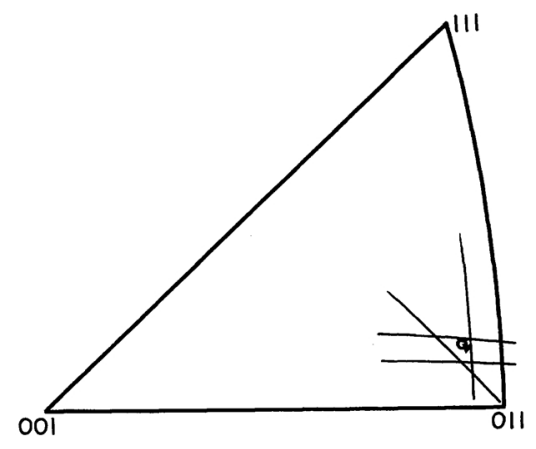

Fig. 7 Habit plane normal referred to the matrix of B2 phase in $\mathrm{Ni}_{31.5} \mathrm{Zn}_{48} \mathrm{Cu}_{20.5}$ alloy. Arcs in the figure represent the traces of normals observed in different specimens. The open circle shows the theoretical habit plane calculated by Kajiwara(21). A closed triangle shows $(2,13,14)_{\mathrm{B} 2}$. 
plane normals determined by the one surface analysis in different thin foils are shown in Fig. 7. They are close to $(2,13,14)_{\mathbf{B} 2}$ and the theoretical habit plane ${ }^{(21)}$.

\section{Discussion}

The martensitic transformation in the ternary $\mathrm{Ni}-\mathrm{Zn}-\mathrm{Cu}$ alloys was studied. The volume change associated with the $\mathrm{L} 1_{\mathrm{o}}$ to $\mathrm{B} 2$ transformation, $\Delta V$, is fairly small (about $0.16-0.48 \%$ ) in the $\mathrm{Ni}-\mathrm{Zn}-\mathrm{Cu}$ alloys, which may be favorable for the thermoelastic martensitic transformation. The axial ratio $(c / a)$ of the $\mathrm{L} 1_{\mathrm{o}}$ lattice in the $\mathrm{Ni}-\mathrm{Zn}-\mathrm{Cu}$ alloys decreases slightly with increase in temperature; this is in good agreement with that reported in the binary $\mathrm{Ni}-\mathrm{Zn}$ alloy ${ }^{(8)}$. In the tetragonal martensite phase in alloys such as $\mathrm{In}-\mathrm{Tl}^{(22)}, \mathrm{Mn}-\mathrm{Cu}^{(23)}$ and $\mathrm{V}_{3} \mathrm{Si}^{(24)}$, the axial ratio has been found to be dependent on temperature; the martensitic transformation in these alloys is close to the 2 nd order transformation, compared with that in the $\beta$ phase alloys $^{(25)}$. The result revealed in Fig. 5 suggests that the $\mathrm{L} 1_{\mathrm{o}}$ to $\mathrm{B} 2$ transformation of the $\mathrm{Ni}-\mathrm{Zn}$ $\mathrm{Cu}$ alloy has slightly the nature of 2 nd order transformation although it is almost of the 1st order. Any temperature dependence of the axial ratio in the martensite phase of the noble metal base $\beta$ phase alloys has not yet been reported. The temperature coefficient of the elastic constant, $\mathrm{d} C^{\prime} / \mathrm{dT}\left(C^{\prime}=\left(C_{11}-C_{12}\right) / 2\right)$, in the $\mathrm{Ni}_{50-x}$ $\mathrm{Zn}_{50} \mathrm{Cu}_{x}$ alloy has been reported to be positive and in the same order with that in the noble metal base $\beta$ phase alloys ${ }^{(26)(27)} . \Delta V$ in $\mathrm{Ni}-\mathrm{Zn}-$ $\mathrm{Cu}$ is also in the same order with that in the $\beta$ phase alloy. Thereby, the nature of the martensitic transformation in the $\mathrm{Ni}-\mathrm{Zn}-\mathrm{Cu}$ alloy is considered to be close to that of the $\beta$ phase alloy, but slightly has the 2 nd order nature.

Kajiwara $^{(21)}$ has analyzed theoretically the crystallography of the $\mathrm{B} 2$ to $\mathrm{L} 1_{\mathrm{o}}$ transformation and shown that the habit plane of the $\mathrm{L1}_{\mathrm{o}}$ martensite changes as a function of the axial ratio $(c / a)$. The traces of habit plane normals determined by the trace analysis are fairly in good agreement with the theoretical habit plane calculated by Kajiwara $^{(21)}$. The habit plane is considered to be close to $(2,13,14)_{\mathbf{B} 2}$ plane in the $\mathrm{Ni}-\mathrm{Zn}-\mathrm{Cu}$ alloy, as shown in Fig. 7. In the $\beta$ phase alloys, the habit plane of the $2 \mathrm{H}$ martensite has been reported to be close to the planes such as $\{122\}_{\beta}$ and $\{133\}_{\beta}$ and that of the 18R (or 9R) martensite to the planes such as $\{155\}_{\beta},\{166\}_{\beta}$ and $\{2,11,12\}_{\beta}{ }^{(28)}$. In the $\mathrm{Ni}-\mathrm{A} 1$ alloy, the habit plane of the $\mathrm{L} 1_{0}$ martensite has been found to be close to $\{2,14$, $15\}_{\text {B2 }}$ plane $^{(4)}$. The observed habit plane normals in the $\mathrm{Ni}-\mathrm{Zn}-\mathrm{Cu}$ alloy are located close to that of the thermoelastic martensite in these alloys.

In the nickel base alloys, the martensitic transformation has been observed in alloys such as $\mathrm{Ni}-\mathrm{Al}, \mathrm{Ni}_{3} \mathrm{Sn}$ and $\mathrm{Ni}-\mathrm{Ti}$, as summarized in Table 2. In alloys such as $\mathrm{Ni}-\mathrm{Al}, \mathrm{Ni}-\mathrm{Zn}$ and $\mathrm{Ni}-\mathrm{Zn}-\mathrm{Cu}$, the structure of martensite phase is

Table 2 Martensitic transformation in the Ni-base alloys. The range of composition and the electron atom ratio $(e / a)$ where the martensitic transformation has been observed is also listed in this table. The $e / a$ of $\mathrm{Ni}-\mathrm{Ti}$ and Ni-Ti-Fe alloys is not shown here because it contains $3 \mathrm{~d}$ electrons.

\begin{tabular}{|c|c|c|c|c|}
\hline $\begin{array}{c}\text { Alloy } \\
\text { system }\end{array}$ & $\begin{array}{l}\text { Change of } \\
\text { structure }\end{array}$ & $\begin{array}{c}\text { Range of } \\
\text { composition/ } \\
\text { at } \%\end{array}$ & $e / a$ & References \\
\hline $\mathrm{Ni}-\mathrm{Al}$ & $\mathrm{B} 2 \rightarrow \mathrm{L} 1_{\mathrm{o}}$ & $34-38 \mathrm{Al}$ & $1.02-1.20$ & (1)-(4) \\
\hline $\mathrm{Ni}-\mathrm{Zn}$ & $\mathrm{B} 2 \rightarrow \mathrm{L} 1_{\mathrm{o}}$ & $48-56 \mathrm{Zn}$ & $0.96-1.12$ & (5)-(8) \\
\hline $\mathrm{Ni}-\mathrm{Zn}-\mathrm{Cu}$ & $\mathrm{B} 2 \rightarrow \mathrm{L} 1_{\mathrm{o}}$ & $\left\{\begin{array}{l}48-56 \mathrm{Zn} \\
0-22 \mathrm{Cu}\end{array}\right.$ & $0.96-1.24$ & $\left\{\begin{array}{l}(9)-(13), \\
\text { This work }\end{array}\right.$ \\
\hline $\mathrm{Ni}_{3} \mathrm{Sn}$ & $\mathrm{DO}_{3} \rightarrow 2 \mathrm{H}$ & $25 \mathrm{Sn}$ & 1.0 & (14) \\
\hline $\mathrm{Ni}-\mathrm{Cu}-\mathrm{Sn}$ & $\mathrm{DO}_{3} \rightarrow 2 \mathrm{H}$ & $\left\{\begin{array}{l}25 \mathrm{Sn} \\
0-18 \mathrm{Cu}\end{array}\right.$ & $1.0-1.18$ & $(15)(16)$ \\
\hline $\mathrm{Ni}-\mathrm{Ti}$ & $\left\{\begin{array}{l}\text { B2 } \rightarrow \text { distorted } \\
\text { B19 }\end{array}\right.$ & $49-51 \mathrm{Ti}$ & - & (29) \\
\hline $\mathrm{Ni}-\mathrm{Ti}-\mathrm{Fe}$ & $\left\{\begin{array}{l}\mathrm{B} 2 \rightarrow \text { intermediate } \\
\text { phase } \rightarrow \text { dist. } \mathrm{B} 19\end{array}\right.$ & $\left\{\begin{array}{l}50 \mathrm{Ti} \\
0-4 \mathrm{Fe}\end{array}\right.$ & 一 & $(30)(31)$ \\
\hline
\end{tabular}




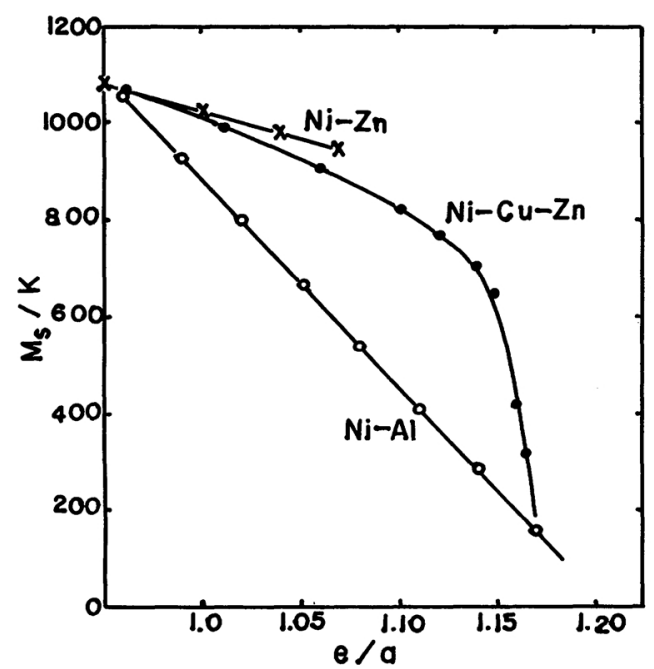

Fig. 8 The starting temperature of the martensitic transformation from $\mathrm{B} 2$ to $\mathrm{L1}_{\mathrm{o}}$ structure upon cooling, $M_{s}$, in nickel base alloys such as $\mathrm{Ni}-\mathrm{Al}^{(3)}$, $\mathrm{Ni}-\mathrm{Zn}^{(5)(18)}$ and $\mathrm{Ni}_{52-x} \mathrm{Zn}_{48} \mathrm{Cu}_{x}^{(10)}$ alloys as a function of the electron atom ratio $(e / a)$.

the $\mathrm{L}_{\mathrm{o}}$ structure. In alloys such as $\mathrm{Ni}_{3} \mathrm{Sn}$ and $\mathrm{Ni}-\mathrm{Cu}-\mathrm{Sn}$, it is the $2 \mathrm{H}$ structure. The martensite phase in these alloys is considered to occur in a range of $e / a$ from about 0.96 to 1.24. The transformations in $\mathrm{Ti}-\mathrm{Ni}$ and $\mathrm{Ti}-\mathrm{Ni}-\mathrm{Fe}$ alloys are very complicated ${ }^{(29)-(31)}$ and then shown briefly in this table.

The starting temperature of the martensitic transformation from the $\mathrm{B} 2$ to $\mathrm{L} 1_{\mathrm{o}}$ structures upon cooling, $M_{s}$, in the $\mathrm{Ni}-\mathrm{Zn}^{(5)}, \mathrm{Ni}-\mathrm{Zn}-$ $\mathrm{Cu}^{(10)}$ and $\mathrm{Ni}-\mathrm{Al}^{(3)}$ alloys is shown in Fig. 8 as a function of the electron atom ratio $(e / a)$. The $M_{s}$ temperature has a tendency to decrease with increase in $e / a$. These results indicate that the $\mathrm{Ll}_{\mathrm{o}}$ structure occurs in a range of $e / a$ below about 1.2 in these alloys. In the noble metal base alloys, the $\beta$ phase (bcc) occurs in a range of $e / a$ near 1.48 and the $\alpha$ phase $(f c c)$ in a range of $e / a$ below about 1.36: this is the so-called Hume-Rothery rule. However, in the nickel base alloys, the disordered $f c c$ phase does not exist in this range of $e / a$, because the ordering energy of atomic pairs in the B2-type ordered phase of nickel base alloys is very large ${ }^{(11)}$. In this case, the martensitic transformation may be favorable for the formation of the closepacked structure such as $\mathrm{L}_{\mathrm{o}}$ in a range of $e / a$ below about 1.2. Figure 9 represents the rela-

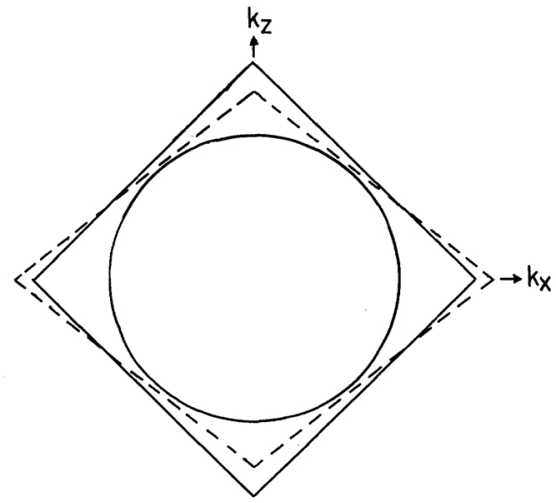

Fig. 9 Relation between the Fermi sphere and the $\{101\}$ Brillouin zone of $b c c$ (real line) and bct (dotted line) lattices in an alloy with $e / a$ of 1.2. In this figure, the Brillouin zone due to the B2-type superstructure is not shown for simplicity, and that of the $\mathrm{L1}_{0}$ structure is denoted by that of $b c t$ with $c / a=1.23$.

tion between the Fermi sphere at $e / a=1.2$ and the Brillouin zones. By the cubic to tetragonal transformation, the (101) Brillouin zone of the B2 structure approaches the Fermi sphere at $e / a=1.2$, as shown in the figure. Then the electronic energy may decrease as a result of the cubic-to-tetragonal transformation. This may be one reason of the $\mathrm{B} 2$ to $\mathrm{L} 1_{\mathrm{o}}$ transformation in alloys such as $\mathrm{Ni}-\mathrm{Al}$ and $\mathrm{Ni}-\mathrm{Zn}-\mathrm{Cu}$. Because the $e / a$ at the phase boundary is not constant as revealed in Fig. 3, the phase stability of the $\mathrm{Ni}-\mathrm{Zn}-\mathrm{Cu}$ alloys may be affected partly by another factor such as the difference in atomic radius among the constituent atoms.

The martensite phase with $2 \mathrm{H}$ structure in the $\mathrm{Ni}_{3} \mathrm{Sn}$ and $\mathrm{Ni}-\mathrm{Cu}-\mathrm{Sn}$ alloys has been found in a range of $e / a$ from about 1 to 1.18 as listed in Table 2. This may also be affected by the decrease of electronic energy due to the B2 to $2 \mathrm{H}$ transformation $^{(15)}$. A more detailed theoretical analysis of the electronic energy is expected to clarify the origin of martensitic transformation in the nickel base alloys.

\section{Acknowledgment}

This work was partly supported by Hyogoken Kagaku-gijutsu Shinko Zaidan. One of the authors (N. N.) expresses his sincere appreciation.

\section{REFERENCES}

(1) K. Enami, S. Nenno and K. Shimizu: Trans. 
Japan Inst. Metals, 14 (1973), 161.

(2) K. Enami and S. Nenno: Met. Trans., 2 (1971), 1478.

(3) J. L. Smialek and R. H. Heheman: Met. Trans., 4 (1973), 1571.

(4) S. Chakravorty and C. M. Wayman: Met. Trans., 7A (1976), 555.

(5) K. Tamaru: Bull. Inst. Phys. Chem. Res. Japan, 11 (1932), 772 (in Japanese).

(6) W. W. Liang, J. W. Franks and Y. A. Chang: Met. Trans., 3 (1972), 2555.

(7) Y. Murakami, S. Kachi and N. Nakanishi: Trans. Japan Inst. Metals., 25 (1984), 19.

(8) K. Schubert: Z. Metallk., 43 (1952), 1.

(9) K. Yamaguchi and K. Nakamura: Bull. Inst. Phys. Chem. Res. Japan, 13 (1934), 89 (in Japanese).

(10) Y. Murakami, S. Shimizu and S. Kachi: Japan. J. Appl. Phys., 14 (1975), 143.

(11) S. Shimizu, Y. Murakami and S. Kachi: J. Phys. Soc. Japan., 41 (1976), 78.

(12) Y. Murakami, S. Kachi and S. Shimizu: New Aspects of Martensitic Transformation, suppl. Trans. JIM, 17 (1976), 147.

(13) Y. Murakami and S. Kachi: Trans. Japan Inst. Metals, 18 (1977), 423.

(14) H. R. Pak, T. Saburi and S. Nenno: J. Japan Inst. Metals, 37 (1973), 1128 (in Japanese).

(15) Y. Watanabe, Y. Murakami and S. Kachi: J. Japan Inst. Metals, 45 (1981), 551 (in Japanese).

(16) Y. Murakami and S. Kachi: Trans. Japan Inst.
Metals, 24 (1983), 9.

(17) L. Delaey, R. V. Krishnan, H. Tas and H. Warlimont: J. Mater. Sci., 9 (1974), 1521.

(18) M. Hansen and K. Anderco: Constitution of Binary Alloys, McGraw Hill, New York, (1958).

(19) H. Suzuki: Sci. Rep. RITU, A6 (1954), 34.

(20) K. Otsuka, C. M. Wayman, N. Nakai, H. Sakamoto and K. Shimizu: Acta Met., 24 (1976), 207.

(21) S. Kajiwara: Japan. J. Appl. Phys., 15 (1976), 923.

(22) L. Guttman: Trans. Met. Soc. AIME, 188 (1950), 1472 .

(23) Z. S. Basinski and J. W. Christian: J. Inst. Metals, 80 (1951), 659.

(24) B. W. Batterman and C. S. Barrett: Phys. Rev., 145 (1966), 296.

(25) N. Nakanishi: Shape Memory Effects in Alloys, ed. by J. Perkins, Plenum Press, New York, (1975), p. 147.

(26) N. Nakanishi: Prog. Mater. Sci., 24 (1979), 145.

(27) Y. Murakami and S. Kachi: Japan. J. Appl. Phys., 13 (1974), 1728.

(28) H. Warlimont and L. Delaey: Prog. Mater. Sci., 18 (1974), 1.

(29) K. Otsuka, T. Sawamura and K. Shimizu: Phys. Status Solidi (a), 5 (1971), 459.

(30) M. Matsumoto and T. Honma: New Aspects of Martensitic Transformation, suppl. Trans. JM, 17 (1976), p. 199.

(31) C. M. Hwang,M.B. Salamon and C. M. Wayman: Phil. Mag., A47 (1983), 177. 